Original Research Paper

\title{
Pelatihan Pembuatan Nata de Pitaya dari Limbah Kulit Buah Naga pada Kelompok Wanita Tani (KWT) Kebun Buah Naga di Desa Tanak Beak Lombok Tengah
}

\author{
Lalu Zulkifli ${ }^{1}$, Mahrus ${ }^{1}$, Prapti Sedijani ${ }^{1}$, Dewa Ayu Citra Rasmi ${ }^{1}$

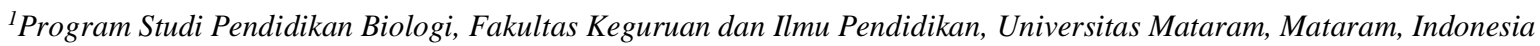

DOI: https://doi.org/10.29303/jpmpi.v3i2.573

Sitasi:. Zulkifli. L., Mahrus., Sedijani, P. \& Rasmi, D. A. C. (2020). Pelatihan Pembuatan Nata de Pitaya dari Limbah Kulit Buah Naga pada Kelompok Wanita Tani (KWT) Kebun Buah Naga di Desa Tanak Beak Lombok Tengah. Jurnal Pengabdian Magister Pendidikan IPA, 3(2)

\section{Article history}

Received: 25 Oktober

Revised: 15 Nopember

Accepted: 30 Desember

*Corresponding Author: Lalu

Zulkifli, Program Studi

Pendidikan Biologi, Fakultas

Keguruan dan Ilmu Pendidikan,

Universitas Mataram, Mataram,

Indonesia;

Email:

lalu_zulkifli@unram.ac.id

\begin{abstract}
Desa Tanak Beak Kec. Batukliang Utara merupakan salah satu sentra penghasil buah naga. Desa ini memiliki Kebun Kelompok Wanita Tani (KWT). Pada waktu panen ini sempat dikunjungi gubernur NTB untuk panen raya buah naga. Buah naga yang banyak di tempat wisata ini, banyak dikonsumsi oleh pengunjung dan kulitnya tidak termanfaatkan serta cenderung sebagai limbah yang mengganggu tempat sekitar. Pada tahap sosialisasi ini hampir semua anggota KWT Kebun buah naga Dusun Dasan Agung hadir. Mereka sangat antusias dalam mengikuti penjelasan terkait manfaat kulit buah naga yang dapat dijadikan sebagai bahan baku pembuatan nata de pitaya. Sambutan mereka sangat baik terkait program pengabdian ini, karena mereka materi ini juga penting dalam mengatasi limbah buah naga yang ketika panen banyak kulit buah naga yang menjadi limbah dan tidak termaafkan dan menjadikan lingkungan sekitar kurang baik. Dalam menyampaikan teknik pembuatan kami sampaikan menggunakan media LCD dengan presentasi PPT, sehingga mereka lebih mudah menangkap pesan dan inti dari tahap-tahap proses dalam pembuatan nata de pitaya. Dalam penjelasan teknik pembuatan nata dari kulit buah ini banyak sekali pertanyaan pertanyaan terkait proses pembuatannya. Setelah selesai penjelasan, diskusi dan tanya jawab, kemudian peserta diajak langsung praktek pembuatan nata de pitaya dari tahap pengambilan kulit, pembersihan sampai pada tahap inkubasi setelah diberikan bakteri starter Acetobacter xylinum. Hasil proses pembuatan kemudian dicuci dan dipotong-potong dan ditimbang. Para peserta sangat berharap kegiatan ini dapat ditindaklanjuti, sehingga dapat sebagai salah satu alternatif pengahasil tambahan keluarga. Mereka sangat berharap bahwa program ini dapat dilanjutkan sampai pada tahap-tahap berikutnya sehingga masyarakat Dusun Dasan Agung dapat sebagai salah satu tempat memproduksi nata de pitaya karena bahan baku cukup tersedia.
\end{abstract}

Keywords: KWT; Kulit buah naga; Desa wisata; Nata de pitaya.

\section{Pendahuluan}

Desa Tanak Beak adalah salah satu desa yang secara administratif masuk dalam wilayah Kecamatan Batukliang Lombok Tengah. Desa Tanak Beak terletak di sebelah utara Kabupaten
Lombok Tengah, berjarak sekitar $25 \mathrm{~km}$ dari Praya (ibu kota kabupaten). Desa Tanak Beak terdiri dari 10 Dusun: yaitu Dusun Tanak Beak Timur, Dusun Tanak Beak Barat, Dusun Ceking, Dusun Mandok, Dusun Parampuan, Dusun Jurang Tangkluk, Dusun Montong Tanggak, Dusun Dasan Agung, Dusun 
Tanak Bengan, Dusun Dasan Agung Kebon Indah (tempat wisata alam buah naga). Desa Tanak Beak dikelilingi oleh Desa Aik Darek Kec. Batu Kliang (Selatan), Desa Karang Sidemen, Kec. Batukliang Utara (Timur), Desa Pemepek Kec. Pringgarata (Barat dan Utara). Jumlah total penduduk yang terdata sampai tahun 2018 adalah 6960 jiwa dengan rincian 3445 laki-laki dan 3515 perempuan. Mata pencaharian masyarakat desa Tanak Beak didominasi oleh petani dan buruh tani (sekitar 60\%) dan diikuti oleh pedagang (Profil Desa Tanak Beak, 2018).

Desa Tanak Beak tergolong cukup berhasil dalam mengembagkan wisata kebun naga khususnya yang berlokasi di Dusun Dasan Agung Kebun Indah. Di lokasi ini terdapat lebih dari 5000 tanaman buah naga pada lahan seluas lebih dari 1 hektar yang dapat memproduksi sekitar 3 Ton untuk sekali panen. Dalam setahun dapat dilakukan 3 kali panen. Khusus di kawasan tersebut buahnya tidak di jual ke pengepul melainkan langsung di konsumsi di tempat oleh para wisatawan. Pengunjung yang berdatangan tidak hanya wisatawan domestik tapi banyak juga dari mancanegara untuk menikmati indahnya alam dan menikmati daging buah naga. Hal ini mengakibatkan banyaknya kulit buah naga yang terbuang dan menjadi limbah perkebunan yang terbuang tidak termanfaatkan.

Buah naga merupakan buah yang banyak digemari oleh masyarakat karena memiliki khasiat dan manfaat serta nilai gizi yang cukup tinggi. Buah naga merah hanya dikonsumsi daging buahnya dalam keadaan segar, sedangkan limbah kulitnya yang berjumlah sekitar 30-35\% dari berat buah tidak dimanfaatkan (Dara et al., 2012; Pribadi et al., 2014). Kulit buah naga merah juga kaya akan sumber polifenol dan antioksidan. Komposisi nilai gizi kandungan gula pada kulit buah naga merah berpotensi sebagai bahan baku pengolahan pangan, seperti olahan sirup kulit buah naga, selai kulit buah naga, manisan kulit buah naga dan nata kulit buah naga (Nata de pitaya).

Pembuatan nata dari kulit buah naga yang memanfaatkan ekstrak kulit buah naga sangat berpotensi untuk menghasilkan produk baru yang merupakan hasil dari aktivitas mikroorganisme, karena dalam limbah kulit buah naga tersebut masih memiliki kandungan yang dapat membentuk nata. Alternatif dari pengolahan limbah kulit buah naga tersebut menjadi nata diharapkan mampu mengurangi limbah yang mencemari lingkungan (Meliawati, 2016). Nata dari ekstrak kulit buah naga memang belum banyak dikenal oleh masyarakat. Hal ini disebabkan karena masyarakat beranggapan bahwa kulit buah naga tidak bisa dimanfaatkan menjadi sesuatu yang berharga dan hanya akan menjadi limbah perkebunan. Nata dari kulit buah naga merah kaya serat dan baik untuk dikonsumsi masyarakat. Selain kaya serat, pengolahan limbah kulit buah naga dapat memberikan peluang usaha kepada masyarakat. Hal ini dapat mengurangi dampak pencemaran lingkungan yang diakibatkan oleh limbah kulit buah naga.

\section{Metode}

\section{Persiapan}

Persiapan rencana program pengabdian pada masyarakat di Desa Tanak Beak tentang penyuluhan dan pelatihan pembuatan nata de pitaya dari limbah kulit buah naga meliputi: persiapan materi penyuluhan dan pelatihan, mengurus surat izin pengabdian, konsolidasi dengan pemerintah desa setempat, Kadus Dasan Agung Kebon Indah dan KWT kebun naga sebagai kelompok masyarakat sasaran.

\section{Pelaksanaan}

Metode yang akan digunakan adalah:

1. Sosialisasi dan penyuluhan terkait limbah kulit buah naga yang merupakan $30 \%$ materi organic buah naga serta kandungannya yang bermanfaat dan dapat dibuat sebagai sumber bahan baku produk olahan yang bernilai ekonomi.

2. Metode praktek langsung pembuatan nata de pitaya dari kulit buah naga.

3. Tahap evaluasi dan pelaporan akan dilakukan kunjungan ke mitra dan masyarakat sasaran di Desa Tanak Beak untuk melihat tindak lanjut dan permasalah yang dihadapi jika ada anggota kelompok masyarakat yang mencoba memulai dan melanjutkan kegiatan usaha pembuatan nata de pitaya.

\section{Hasil dan Pembahasan}

\section{Analisa Hasil}

1. Sosialisasi dan penyuluhan terkait limbah kulit buah naga

Pada tahap sosialisasi ini hampir semua anggota KWT Kebun buah naga Dusun Dasan 
Agung hadir (Gambar 1). Mereka sangat antusias dalam mengikuti penjelasan terkait manfaat kulit buah naga yang dapat dijadikan sebagai bahan baku pembuatan nata de pitaya. Sambutan mereka sangat baik terkait program pengabdian ini, karena mereka materi ini juga penting dalam mengatasi limbah buah naga yang ketika panen banyak kulit buah naga yang menjadi limbah dan tidak termaafkan dan menjadikan lingkungan sekitar kurang baik. Dalam menyampaikan teknik pembuatan kami sampaikan menggunakan media LCD dengan presentasi PPT, sehingga mereka lebih mudah menangkap pesan dan inti dari tahaptahap proses dalam pembuatan nata de pitaya. Tahap awal adalah sterilisasi alat dan bahan agar pembuatan nata dapat berhasil sebagaimana diharapkan. Dalam penjelasan teknik pembuatan nata dari kulit buah ini banyak sekali pertanyaan pertanyaan terkait proses pembuatannya secara detail. Disamping itu mereka bertanya sampai pada tahap produksi dan kualitas standar mutu nata dan juga pemasaran. Kami dari tim menjelaskan dengan baik pertanyaan-pertanyaan dari partisipan tersebut. Mereka sangat berharap bahwa program ini dapat dilanjutkan sampai pada tahap-tahap berikutnya sehingga masyarakat Dusun Dasan Agung dapat sebagai salah satu tempat memproduksi nata de pitaya karena bahan baku cukup tersedia.

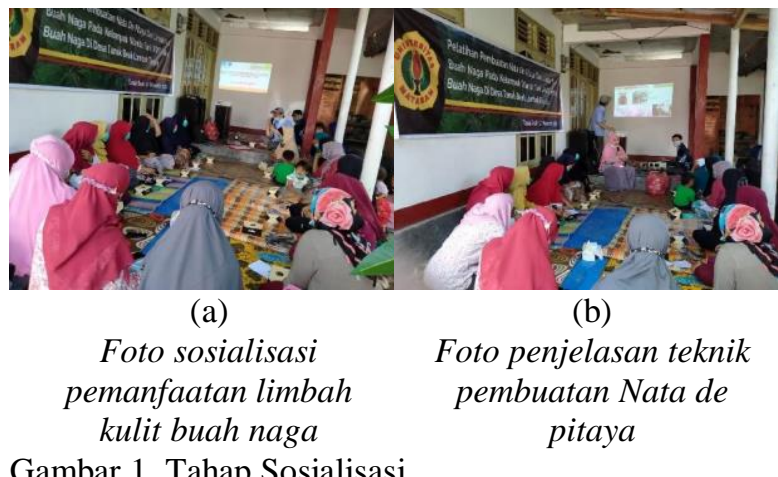

Gambar 1. Tahap Sosialisasi

2. Metode praktek langsung pembuatan nata de pitaya dari kulit buah naga.

Setelah selesai penjelasan dan diskusi dan tanya jawab, kemudian peserta diajak langsung praktek pembuatan nata de pitaya dari tahap pengambilan kulit, pembersihan sampai pada tahap inkubasi setelah diberikan bakteri starter A.xylinum (Gambar 2).

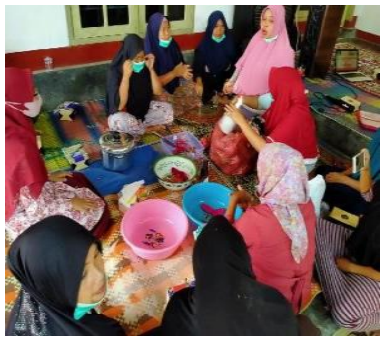

Foto pembuatan Nata de pitaya

Gambar 2. Tahap Inkubasi

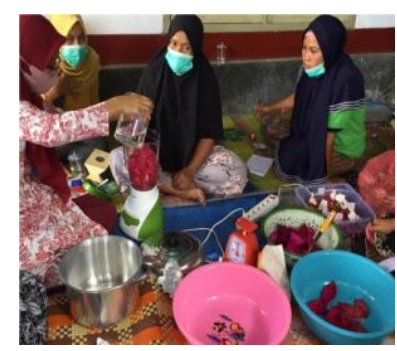

3. Tahap evaluasi hasil pembuatan nata

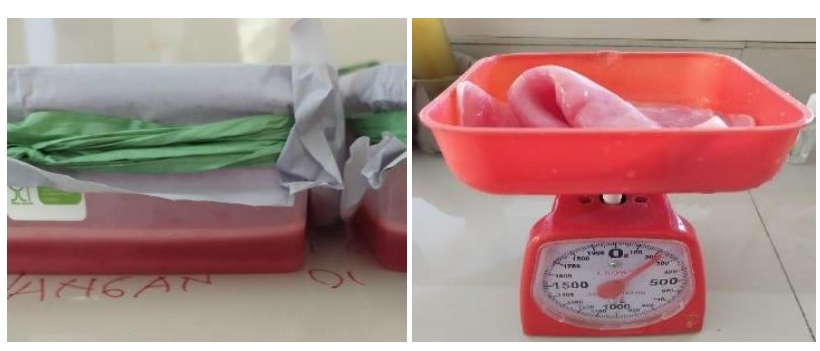

Inkubasi pada hari ke 9

(a)

Nata di ukur berat awalnya

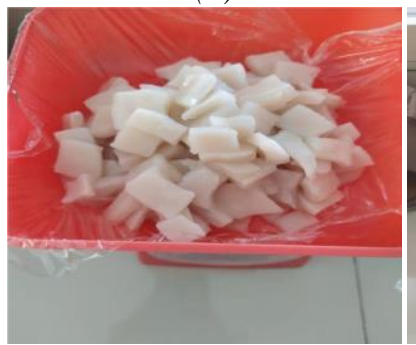

Penampakan nata de pitaya setelah dipotongpotong

(c)

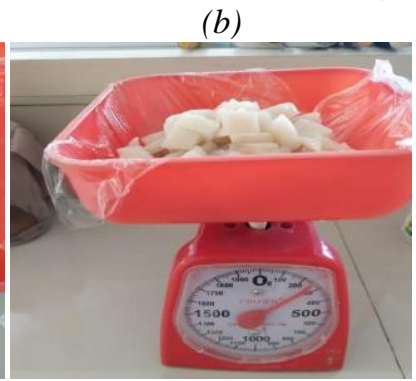

Setelah dicuci dengan air mengalir dan diukur berat akhirnya

(d)

Gambar 3. Tahap Evaluasi

Para peserta sangat berharap kegiatan ini dapat ditindak lanjuti, sehingga dapat sebagai salah satu alternatif penghasilan tambahan keluarga.

\section{Faktor Pendorong}

Desa Tanak Beak tergolong cukup berhasil dalam mengembagkan wisata kebun naga khususnya yang berlokasi di Dusun Dasan Agung Kebun Indah. Di lokasi ini terdapat lebih dari 5000 tanaman buah naga pada lahan seluas lebih dari 1 hektar yang dapat memproduksi sekitar 3 Ton untuk sekali panen. Dalam setahun dapat dilakukan 3 kali panen. Khusus di kawasan tersebut buahnya tidak di jual ke pengepul melainkan langsung di konsumsi di tempat oleh para wisatawan. Pengunjung yang berdatangan tidak hanya wisatawan domestik tapi banyak juga dari 
mancanegara untuk menikmati indahnya alam dan menikmati daging buah naga. Hal ini mengakibatkan banyaknya kulit buah naga yang terbuang dan menjadi limbah perkebunan yang terbuang tidak termanfaatkan.

Pembuatan nata dari kulit buah naga yang memanfaatkan ekstrak kulit buah naga sangat berpotensi untuk menghasilkan produk baru yang merupakan hasil dari aktivitas mikroorganisme, karena dalam limbah kulit buah naga tersebut masih memiliki kandungan yang dapat membentuk nata. Alternatif dari pengolahan limbah kulit buah naga tersebut menjadi nata diharapkan mampu mengurangi limbah yang mencemari lingkungan (Meliawati, 2016). Nata dari ekstrak kulit buah naga memang belum banyak dikenal oleh masyarakat. Hal ini disebabkan karena masyarakat beranggapan bahwa kulit buah naga tidak bisa dimanfaatkan menjadi sesuatu yang berharga dan hanya akan menjadi limbah perkebunan. Nata dari kulit buah naga merah kaya serat dan baik untuk dikonsumsi masyarakat. Selain kaya serat, pengolahan limbah kulit buah naga dapat memberikan peluang usaha kepada masyarakat. Hal ini dapat mengurangi dampak pencemaran lingkungan yang diakibatkan oleh limbah kulit buah naga.

\section{Faktor Penghambat}

Dalam pelaksanaan kegiatan ini, Tim tidak mendapatkan faktor penghambat dalam sosialisasi dan praktek pembuatan. Untuk aplikasi untuk skala rumahan di masa yang akan datang adalah perlunya pemahaman masyarakat terkait penting sterilisasi bahan dan alat agar proses pembuatan nata berjalan dengan baik.

\section{Kesimpulan}

Pelaksanaan program pengabdian masyarakat di kelompok wanita tani (KWT) kebun buah naga di Dusun Dasan Agung Desa Tanak Beak Lombok Tengah telah berhasil dilakukan dengan baik. Masyarakat sasaran sangat antusis dalam mengikuti kegiatan dari awal sampai akhir. Mereka sangat berharap bahwa program ini dapat dilanjutkan sampai pada tahap-tahap berikutnya sehingga masyarakat Dusun Dasan Agung dapat sebagai salah satu tempat memproduksi nata de pitaya karena bahan baku cukup tersedia. Program ini ke depan perlu diperkuat dengan kerjasama dari lembaga terkait misalnya pemda, pihak perguruan tinggi dan lainnya dalam pemberdayaan ekonomi masyarakat.

\section{Ucapan Terima Kasih}

Penulis mengucapkan terima kasih kepada Rektor Universitas Mataram yang telah memberi dukungan finansial terhadap pengabdian ini.

\section{Daftar Pustaka}

Dara. Widia, Shinta, D.Y. dan Saputra, R. (2012). Pemanfaatan Limbah Kulit Buah Naga Merah (Hylocereus Costaricensis) Sebagai Pewarna Kerupuk Merah, Prosiding Seminar Perhimpunan Ahli Teknologi Pangan Indonesia Cabang Sumatera Barat 2012 Food and Renewable Energy for Better Life. Agritech Press Fakultas Teknologi Pertanian-Universitas Andalas.

Melina, M.M. (2016). Pengaruh Penggunaan Filtrat Kecambah Kacang Hijau Sebagai Sebagai Sumber Nitrogen Alternatif Terhadap Karakteristik Nata de Besusu, Universitas Sanata Dharma, Yogyakarta.

Pribadi, Y, S., Sukatiningsih., Sari, P. (2014). Formulasi Tablet Effervescent Berbahan Baku Kulit Buah Naga Merah (Hylocereus polyrhizuz) dan Buah Salam (Syzygium polyanthum Wight. Walp). Berkala Ilmiah Pertanian. 1 (4). 